\title{
Long-term Clinical Outcomes and Quality of Life in Elderly Patients Treated with Interspinous Devices for Lumbar Spinal Stenosis
}

\author{
Massimo Miscusi ${ }^{1}$ \\ Sokol Trungu ${ }^{2}$ Stefano Forcato ${ }^{1}$ \\ Antonino Raco ${ }^{2}$ \\ ${ }^{1}$ NESMOS Department, Sapienza University of Rome, Rome, Italy \\ ${ }^{2}$ NESMOS Department, Sapienza University of Rome, Sant'Andrea \\ Hospital, Rome, Italy \\ 3 Department of Medico-Surgical Sciences and Biotechnologies, \\ Sapienza University of Rome, Rome, Italy \\ ${ }^{4}$ Department of Neurosurgery, Catholic University of Rome, \\ Rome, Italy
}

Alessandro Ramieri ${ }^{3}$

Filippo Maria Polli ${ }^{4}$

J Neurol Surg A 2018;79:139-144.

\begin{abstract}
Address for correspondence Sokol Trungu, MD, NESMOS Department, Sapienza University of Rome, Via Campaldino 16, Rome 00162, Italy (e-mail: s_trungu@hotmail.com).
\end{abstract}

\begin{abstract}
Keywords

- interspinous device

- lumbar stenosis

- minimally invasive surgery

- elderly patients

- neurogenic claudication

Background and Objective Lumbar spinal stenosis (LSS) is a common degenerative condition that occurs in the spine with increasing age. Clinically, LSS causes a progressive reduction in walking autonomy, resulting in a poor quality of life and impaired functional capacity. The aim of this study was to evaluate the clinical outcome and quality of life of elderly patients presenting with LSS and associated comorbidities after a 5-year follow-up who were treated with an interspinous process device (IPD). Material and Methods Sixty patients $>75$ years of age presenting with symptomatic degenerative LSS were included. All were treated with an IPD under local anesthesia. American Society of Anesthesiology score, Zurich Claudication Questionnaire, and Short Form 36 were evaluated pre- and postoperatively and at the follow-up visit each year for 5 years.

Results The mean surgery time while under local anesthesia was 20 minutes. Fortyeight patients were followed for 5 years. Significant clinical improvements in all outcome scores $(p<0.05)$ both postoperatively or at follow-up were found.

Conclusions IPD seems to be an effective and safe treatment for LSS in elderly patients with general comorbidities. In our study, all followed up patients had a meaningful improvement of their quality of life even at 5 years after surgery.
\end{abstract}

\section{Introduction}

Lumbar spinal stenosis (LSS) is a common degenerative condition that occurs in the spine with increasing age. It is caused by degeneration of the intervertebral disk and hypertrophy of the facet joints and ligamentum flavum. Clinically, LSS causes a progressive reduction in walking autonomy and can be associated with acute or chronic signs of

received

September 11, 2016

accepted after revision

May 24, 2017

published online

July 27, 2017 radiculopathy, resulting in a poor quality of life and impaired functional capacity. ${ }^{1-4}$

Nonoperative therapies such as steroidal or nonsteroidal anti-inflammatory drugs, analgesics, and physical therapy can be prescribed initially and provide some benefits, ${ }^{5}$ but when symptoms become disabling, surgical treatment is the best option. Decompressive laminectomy or laminotomy are the standard treatments with good clinical outcomes reported. ${ }^{6-12}$

(c) 2018 Georg Thieme Verlag KG Stuttgart · New York
DOI https://doi.org/ 10.1055/s-0037-1604280. ISSN 2193-6315. 
In the past decade, interspinous process devices (IPDs) have been used more commonly to treat LSS. IPDs, which can be inserted using a minimally invasive procedure, allow distraction of the interlaminar yellow ligament with a consequent indirect opening of the interspace and neural foramens. ${ }^{13-15}$ The final effect of this ligamentotaxis is the central decompression of the dural sac and the intraforaminal part of the nerve roots, with improvement of symptoms and preservation of lumbar spine stability, which may be lost in cases of laminoarthrectomy.

Compared with standard open surgery, this minimally invasive procedure is the best indication in cases of monosegment central stenosis and/or foraminal stenosis, which is mainly caused by yellow ligament hypertrophy. In cases of severe spondylosis or facet hypertrophy with stenosis of the lateral recess, mobile or more than grade 1 spondylolisthesis, or in patients with obesity, IPDs are generally not indicated.

Nevertheless, IPDs may offer great advantages in selected cases compared with standard open surgery. The procedure can be performed under local anesthesia, the operating time is significantly reduced, and there is no risk of neural injury. Furthermore, the anatomical structures, except for the interspinous ligament, are spared. ${ }^{16-19}$ These characteristics may make IPD an option for elderly patients with significant general comorbidities.

The aim of this study was to evaluate the long-term clinical outcomes and quality of life of elderly patients with LSS who underwent minimally invasive surgery with IPD implantation for degenerative lumbar stenosis.

\section{Materials and Methods}

Between January 2008 and December 2010, 60 consecutive elderly patients $>75$ years of age, with radiologic mild or moderate and symptomatic central LSS, presenting with intermittent claudication with a significant reduction in walking autonomy, lower back pain typically relieved by lumbar flexion, with or without radicular extension and numbness, were included.

Patients with grade II to IV spondylolisthesis, frank instability demonstrated with dynamic radiographs, degenerative sagittal deformity with lumbar segmental kyphosis, severe LSS, active oncologic systemic disease, severe osteoporosis ( $\mathrm{T}$ score $\geq 3$ ), or previous spinal surgery with fusion were excluded.

All patients underwent preoperative neurologic assessments including American Society of Anesthesiologists (ASA) score, and clinical outcomes were assessed with the Zurich Claudication Questionnaire (ZCQ) and Short Form 36 (SF-36). ${ }^{20-23}$

All patients underwent IPD implantation while under local anesthesia. The patient was placed in a prone position, the spinous processes of the involved segments were exposed with the aid of intraoperative fluoroscopy through a small median posterior incision, and the IPD was positioned. The X-STOP (Medtronic, Memphis, Tennessee, United States) was used in 22 cases, the Bacjac (Pioneer Surgical Technology, Inc., Marquette, Michigan, United States) was used in 25 cases, and the Impala (SIGNUS Medizintechnik GmbH, Alzenau, Germany) in 13 cases.
Evaluations of general and neurologic conditions, ASA score, ZCQ and SF-36 were collected pre- and postoperatively, and after long-term follow-up (mean time: 52 months; range: 24-64 months).The clinical outcomes were analyzed, and statistical analyses were performed using SPSS v.15 software (Chicago, Illinois, United States). A $p$ value $<0.05$ was considered statistically significant.

\section{Results}

The mean patient age was 80.1 years (range: $75-86$ years). There were 36 women and 24 men. Based on the ASA classification, six patients (10\%) were assigned grade $2 ; 38$ patients $(63.3 \%)$, grade 3 ; and 16 patients $(26.7 \%)$, grade 4. - Table 1 summarizes all patients' medical records including clinical and radiologic data.

The L4-L5 level was involved in 48 patients $(80 \%)$ (-Fig. 1), L3-L4 in 10 patients (16.7\%), L5-S1 in 9 patients (15\%), and L2-L3 in 5 patients (8.3\%); 12 patients (20\%) underwent implantation of two devices. All procedures were performed under local anesthesia. The mean surgery time was 20 minutes (range: 18-30 minutes). No blood transfusions were needed. All patients were discharged on the same day as the procedure or the day after.

Intraoperative fracture of the spinous process occurred in two patients (3.3\%); in such cases, the procedure was aborted and patients underwent laminotomy under general anesthesia in a second operation, after having signed an informed

Table 1 Patients' characteristics

\begin{tabular}{|c|c|c|}
\hline & $N$ & Range \\
\hline \multicolumn{3}{|l|}{$\operatorname{Sex}(\%)$} \\
\hline$M$ & $24(40)$ & \\
\hline $\mathrm{F}$ & $36(60)$ & \\
\hline Age, y & 80.1 & $75-86$ \\
\hline \multicolumn{3}{|l|}{ ASA (\%) } \\
\hline 1 & - & \\
\hline 2 & $6(10)$ & \\
\hline 3 & $38(63.3)$ & \\
\hline 4 & $16(26.7)$ & \\
\hline \multicolumn{3}{|l|}{ IPD (\%) } \\
\hline Single level & $48(80)$ & \\
\hline Two levels & $12(20)$ & \\
\hline \multicolumn{3}{|l|}{ Level (\%) } \\
\hline L2-L3 & $5(8.3)$ & \\
\hline L3-L4 & $10(16.7)$ & \\
\hline L4-L5 & $48(80)$ & \\
\hline L5-S1 & $9(15)$ & \\
\hline \multicolumn{3}{|l|}{ Surgical data } \\
\hline Operative time, $\min$ & 20 & $18-30$ \\
\hline
\end{tabular}

Abbreviations: ASA, American Anesthesiologist Association (score); $\mathrm{F}$, female; IPD, interspinous process device; M, male. 


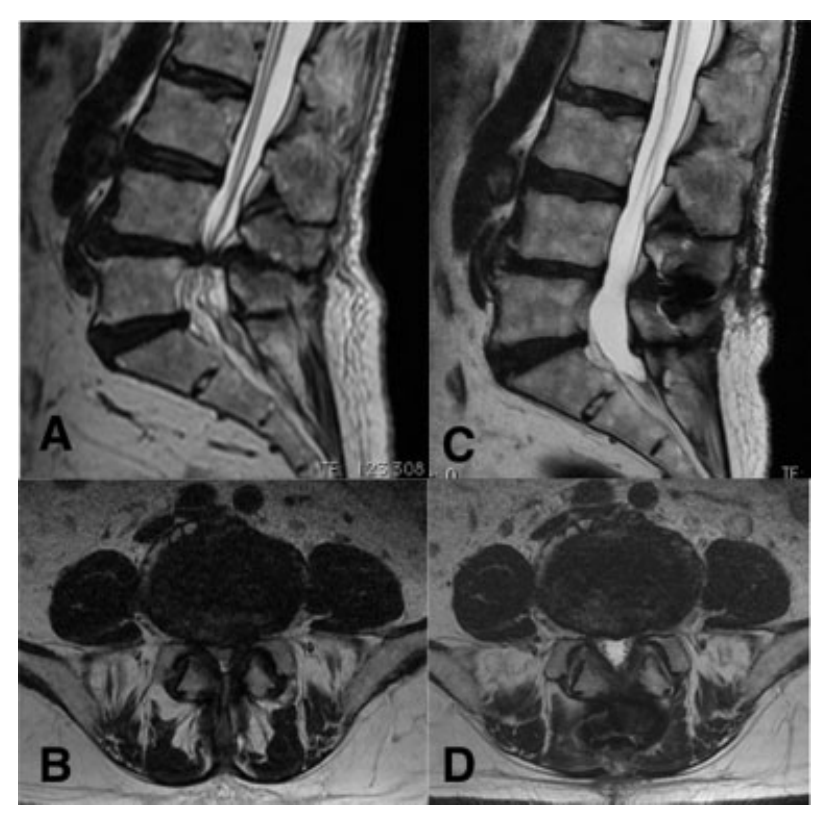

Fig. 1 (a, b) Sagittal and axial T2-weighted magnetic resonance imaging (MRI) scans showing L4-L5 lumbar degenerative stenosis in an 87-year-old patient. (c, d) Sagittal and axial T2-weighted postoperative MRI scans demonstrating the opening of the lumbar canal, mainly due to the ligamentotaxis of the yellow ligament.

consent for the higher risk of complications due to the general anesthesia. Patients who experienced an intraoperative fracture were excluded from the follow-up study. Perioperative complications occurred in three patients; one had a subcutaneous blood collection, and two experienced superficial skin infections. All were treated successfully.

Four patients were excluded from the study because they died 18,23, 24, and 32 months after the procedure of cardiovascular disease such as heart failure, stroke, and respiratory distress. Causes of death were not related to spinal surgery or to their degenerative spine disease.

At the latest follow-up (mean time: 58 months; range: 52-66 months), no complications such as dislocation or rupture of the devices or deep infections had occurred.

-Fig. 2 lists the results of the SF-36 questionnaire. During the early follow-up, patients improved up to 7.9 points on the physical scale compared with the preoperative score, with a slight decrease to 40.1 points at the late follow-up $(p<0.05)$. The best score on the psychological scale was 56.7, with a decrease at later follow-up visits that improved up to 7.9 points compared with the preoperative status $(p<0.05)$. Results of the ZCQ questionnaires (-Fig. 3) demonstrated significant improvement in symptom severity, physical function, and patient satisfaction at the latest follow-up visit.

\section{Discussion}

Spinal degenerative stenosis typically affects elderly patients. These patients usually present with severe comorbidities that are considered risk factors for poor outcomes after laminectomy. ${ }^{24-28}$ Furthermore, poor general condition or diseases involving cardiopulmonary function can impede surgery

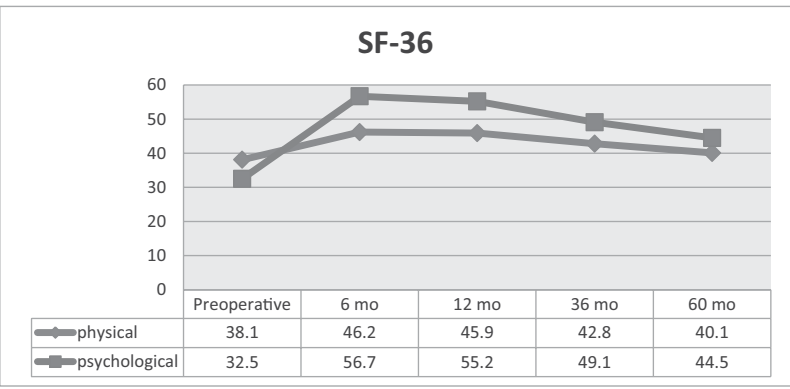

Fig. 2 Results of Short Form 36 (SF-36) questionnaire (physical and psychological scale) preoperatively and at follow-up $(6,12,36$, and 60 months) $(p<0.05)$.

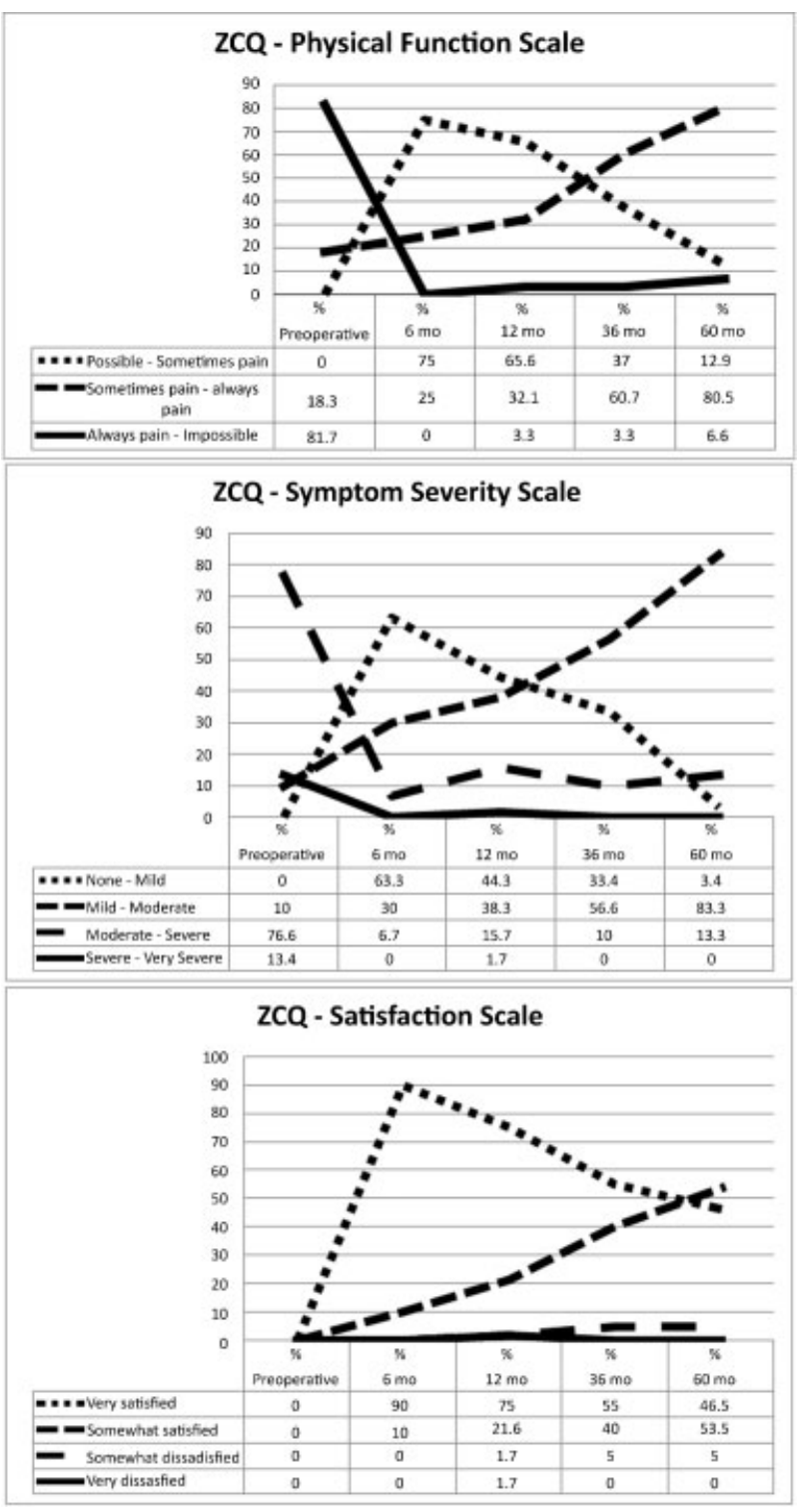

Fig. 3 Results of Physical Function Scale, Symptom Severity Scale, and Satisfaction Scale of the Zurich Claudication Questionnaire (ZCQ) preoperatively and at follow-up $(6,12,36$, and 60 months $)(p<0.05)$. 
performed under general anesthesia. In such patients, conservative treatment is generally preferred as the first choice but is not always effective, especially in cases with persistent and worsening symptoms such as severe intermittent claudication. $^{6-9}$

Minimally invasive approaches have been proposed in the literature as the main treatment for degenerative lumbar stenosis in elderly patients to minimize the risk of complications, especially in patients with severe comorbidities. ${ }^{29}$ In our series, $26.7 \%$ of patients presented an ASA score of 4 . Although blood pressure and oxygenation can be more tightly controlled in patients under general anesthesia compared with local anesthesia, particularly with patients in the prone position, in our experience, patients with significant impairment of cardiopulmonary function tolerate better a fast surgical procedure with local anesthesia. Furthermore, avoiding general anesthesia reduces duration of hospital stay and costs. ${ }^{30,31}$ Insertion of an IPD is a fast and safe procedure that can be performed under local anesthesia and requires only a minor skin incision and muscle retraction.

From a biomechanical standpoint, IPDs can achieve indirect decompression of the dural sac by ligamentotaxis of the yellow ligament, attained through distraction of the posterior elements. ${ }^{13-15}$ Although the results in terms of an anatomical opening in the spinal canal cannot be compared with those obtained by open surgery, significant clinical and functional improvement can be achieved.

In the literature there have been criticisms about IPD use regarding a possible "kyphotic" effect of lumbar segments due to the distraction of the posterior elements. The reckless use of IPDs for all degenerative lumbar diseases is probably the cause of the reported failures. ${ }^{32,33}$ Patients with both frank instability or severe spondylolisthesis, or sagittal segmental deformity, as in our series, are not suitable for an IPD.

Several studies demonstrated that when it is the correct choice, IPDs are as safe and effective as laminectomy to treat degenerative spines in elderly patients. ${ }^{33,34}$ Furthermore, the literature confirms better outcomes with IPDs, even over the long term, compared with conservative treatment. ${ }^{35}$

We believe IPDs should be used in elderly patients with mono- or bisegmental stenosis due to yellow ligament hypertrophy who have severe comorbidities that put them at risk for general perioperative procedures. Our treatment protocol is based on a minimally invasive one-day surgery performed under local anesthesia. The aim of this minimally invasive approach is to relieve the neurologic symptoms that are typical of degenerative conditions and to reestablish the patient's autonomy, enabling them to walk an acceptable distance without being exposed to the risks related to surgery under general anesthesia.

Our results demonstrate that good clinical outcomes can be achieved after 6 months and later follow-ups as assessed by the ZCQ and SF-36 questionnaires. No surgery-related complications were recorded, even in patients with severe comorbidities (i.e., high ASA score). The results of the latest follow-up in terms of clinical outcomes and quality of life have confirmed that IPDs are safe and should always be considered an alternative treatment for LSS in elderly patients with severe comorbidities.

Possible complications of IPDs reported in the literature include subsidence, spinous process fracture, adjacent segment degeneration, persistence of symptoms, and infections; cost effectiveness is also reported. ${ }^{36-40}$ In our series, two patients had a spinous process fracture during the IPD implantation procedure that was facilitated by severe osteoporosis or ossification of the interspinous ligaments, which narrows the interspinous space and impedes implantation of the IPD. Interestingly, no patients in the present series presented a postoperative mobilization of their IPD and spinous process fracture. A critical point to avoid such complications should be the choice of the correct IPD size IPD during implantation.

Two patients presented with superficial wound infections that were related to severe diabetes, and two other patients who complained of persistent symptoms after IPD implantation underwent a laminotomy and laminectomy, respectively, after 12 and 14 weeks, respectively. In these cases, the spinal stenosis was more lateral and associated with articular facet hypertrophy; therefore, the indication for an IPD implant was not totally correct. Nevertheless, the devices were easily removed, and a standard surgical approach to decompress the neural elements was easily completed.

Interestingly, unlike the literature, our series did not include cases of unsuccessful treatment, and we did not perform any second surgeries via an open standard access. Such results seem due to our strict criteria of patients. We did not perform treatment on patients with the following clinical background: grade II to IV spondylolisthesis and instability demonstrated with dynamic radiographs, degenerative sagittal deformity with lumbar segmental kyphosis, severe LSS, active systematic oncologic disease, severe osteoporosis ( $\mathrm{T}$ score $\geq 3$ ), or previous spinal surgery with fusion. Furthermore, the choice of the correct size of IPD seems to be a critical point to avoid poor results in term of neurologic recovery and spinous process fractures. $^{41}$

Different randomized controlled trials have compared IPDs with laminectomy or laminotomy. These studies concluded that both techniques are appropriate for the treatment of LSS. ${ }^{16-19}$ Although IPDs have different advantages (shorter operation time, less blood loss, shorter hospital stay), they have higher reintervention rates compared with decompressive surgery. ${ }^{39,40}$ Nevertheless, in our experience, given a careful selection of patients, IPDs can be considered an effective alternative to the standard surgical approach.

\section{Conclusions}

Our results demonstrate that implantation of IPDs is an effective and safe minimally invasive procedure for treating mono- or bisegmental degenerative lumbar stenosis in elderly patients presenting with severe comorbidities. Rigid inclusion and exclusion criteria seem to be critical factors to obtain good results in such a group of patients. 


\section{References}

1 Amundsen T, Weber H, Lilleås F, Nordal HJ, Abdelnoor M, Magnaes B. Lumbar spinal stenosis. Clinical and radiologic features. Spine 1995;20(10):1178-1186

2 Evans JG. Neurogenic intermittent claudication. BMJ 1964;2 (5415):985-987

3 Porter RW. Spinal stenosis and neurogenic claudication. Spine 1996;21(17):2046-2052

4 de Graaf I, Prak A, Bierma-Zeinstra S, Thomas S, Peul W, Koes B. Diagnosis of lumbar spinal stenosis: a systematic review of the accuracy of diagnostic tests. Spine 2006;31(10):1168-1176

5 Simotas AC. Nonoperative treatment for lumbar spinal stenosis. Clin Orthop Relat Res 2001;(384):153-161

6 Weinstein JN, Tosteson TD, Lurie JD, et al; SPORT Investigators. Surgical versus nonsurgical therapy for lumbar spinal stenosis. N Engl J Med 2008;358(08):794-810

7 Weinstein JN, Tosteson TD, Lurie JD, et al. Surgical versus nonoperative treatment for lumbar spinal stenosis four-year results of the Spine Patient Outcomes Research Trial. Spine 2010;35(14): 1329-1338

8 Malmivaara A, Slätis P, Heliövaara M, et al; Finnish Lumbar Spinal Research Group. Surgical or nonoperative treatment for lumbar spinal stenosis? A randomized controlled trial. Spine 2007;32 (01):1-8

9 Chang Y, Singer DE, Wu YA, Keller RB, Atlas SJ. The effect of surgical and nonsurgical treatment on longitudinal outcomes of lumbar spinal stenosis over 10 years. J Am Geriatr Soc 2005;53(05): 785-792

10 Katz JN, Lipson SJ, Chang LC, Levine SA, Fossel AH, Liang MH. Seven- to 10-year outcome of decompressive surgery for degenerative lumbar spinal stenosis. Spine 1996;21(01):92-98

11 Kovacs FM, Urrútia G, Alarcón JD. Surgery versus conservative treatment for symptomatic lumbar spinal stenosis: a systematic review of randomized controlled trials. Spine 2011;36(20): E1335-E1351

12 Atlas SJ, Keller RB, Wu YA, Deyo RA, Singer DE. Long-term outcomes of surgical and nonsurgical management of lumbar spinal stenosis: 8 to 10 year results from the Maine lumbar spine study. Spine 2005;30(08):936-943

13 Wilke HJ, Drumm J, Häussler K, Mack C, Steudel WI, Kettler A. Biomechanical effect of different lumbar interspinous implants on flexibility and intradiscal pressure. Eur Spine J 2008;17(08): 1049-1056

14 Wiseman CM, Lindsey DP, Fredrick AD, Yerby SA. The effect of an interspinous process implant on facet loading during extension. Spine 2005;30(08):903-907

15 Siddiqui M, Karadimas E, Nicol M, Smith FW, Wardlaw D. Influence of X Stop on neural foramina and spinal canal area in spinal stenosis. Spine 2006;31(25):2958-2962

16 Moojen WA, Arts MP, Brand R, Koes BW, Peul WC. The Felix-trial. Double-blind randomization of interspinous implant or bony decompression for treatment of spinal stenosis related intermittent neurogenic claudication. BMC Musculoskelet Disord 2010; 11(11): 100

17 Strömqvist BH, Berg S, Gerdhem P, et al. X-stop versus decompressive surgery for lumbar neurogenic intermittent claudication: randomized controlled trial with 2-year follow-up. Spine 2013;38(17):1436-1442

18 Beyer F, Yagdiran A, Neu P, Kaulhausen T, Eysel P, Sobottke R. Percutaneous interspinous spacer versus open decompression: a 2-year follow-up of clinical outcome and quality of life. Eur Spine J 2013;22(09):2015-2021

19 Moojen WA, Arts MP, Jacobs WC, et al; Leiden-The Hague Spine Intervention Prognostic Study Group. Interspinous process device versus standard conventional surgical decompression for lumbar spinal stenosis: randomized controlled trial. BMJ 2013; 347:f6415
20 Stucki G, Daltroy L, Liang MH, Lipson SJ, Fossel AH, Katz JN. Measurement properties of a self-administered outcome measure in lumbar spinal stenosis. Spine 1996;21(07):796-803

21 Copay AG, Glassman SD, Subach BR, Berven S, Schuler TC, Carreon LY. Minimum clinically important difference in lumbar spine surgery patients: a choice of methods using the Oswestry Disability Index, Medical Outcomes Study questionnaire Short Form 36, and pain scales. Spine J 2008;8(06):968-974

22 Pratt RK, Fairbank JC, Virr A. The reliability of the Shuttle Walking Test, the Swiss Spinal Stenosis Questionnaire, the Oxford Spinal Stenosis Score, and the Oswestry Disability Index in the assessment of patients with lumbar spinal stenosis. Spine 2002;27(01):84-91

23 Brussee P, Hauth J, Donk RD, Verbeek AL, Bartels RH. Self-rated evaluation of outcome of the implantation of interspinous process distraction (X-Stop) for neurogenic claudication. Eur Spine J 2008; 17(02):200-203

24 Carragee EJ. The increasing morbidity of elective spinal stenosis surgery: is it necessary? JAMA 2010;303(13):1309-1310

25 Deyo RA, Mirza SK, Martin BI, Kreuter W, Goodman DC, Jarvik JG. Trends, major medical complications, and charges associated with surgery for lumbar spinal stenosis in older adults. JAMA 2010;303(13):1259-1265

26 Fu KM, Smith JS, Polly DW Jr, et al; Scoliosis Research Society Morbidity and Mortality Committee. Correlation of higher preoperative American Society of Anesthesiology grade and increased morbidity and mortality rates in patients undergoing spine surgery. J Neurosurg Spine 2011;14(04):470-474

27 Fu KM, Smith JS, Polly DW Jr, et al. Morbidity and mortality in the surgical treatment of 10,329 adults with degenerative lumbar stenosis. J Neurosurg Spine 2010;12(05):443-446

28 Deyo RA, Cherkin DC, Loeser JD, Bigos SJ, Ciol MA. Morbidity and mortality in association with operations on the lumbar spine. The influence of age, diagnosis, and procedure. J Bone Joint Surg Am 1992;74(04):536-543

29 Rosen DS, O'Toole JE, Eichholz KM, et al. Minimally invasive lumbar spinal decompression in the elderly: outcomes of 50 patients aged 75 years and older. Neurosurgery 2007;60(03): 503-509; discussion 509-510

30 De Rojas JO, Syre P, Welch WC. Regional anesthesia versus general anesthesia for surgery on the lumbar spine: a review of the modern literature. Clin Neurol Neurosurg 2014;119:39-43

31 Skidmore G, Ackerman SJ, Bergin C, et al. Cost-effectiveness of the $\mathrm{X}-\mathrm{STOP}{ }^{\circledR}$ interspinous spacer for lumbar spinal stenosis. Spine 2011;36(05):E345-E356

32 Lindsey DP, Swanson KE, Fuchs P, Hsu KY, Zucherman JF, Yerby SA. The effects of an interspinous implant on the kinematics of the instrumented and adjacent levels in the lumbar spine. Spine 2003;28(19):2192-2197

33 Schulte LM, O'Brien JR, Matteini LE, Yu WD. Change in sagittal balance with placement of an interspinous spacer. Spine 2011;36 (20):E1302-E1305

34 Zucherman JF, Hsu KY, Hartjen CA, et al. A multicenter, prospective, randomized trial evaluating the X STOP interspinous process decompression system for the treatment of neurogenic intermittent claudication: two-year follow-up results. Spine 2005;30(12): 1351-1358

35 Hsu KY, Zucherman JF, Hartjen CA, et al. Quality of life of lumbar stenosis-treated patients in whom the X STOP interspinous device was implanted. J Neurosurg Spine 2006;5(06):500-507

36 Kuchta J, Sobottke R, Eysel P, Simons P. Two-year results of interspinous spacer (X-Stop) implantation in 175 patients with neurologic intermittent claudication due to lumbar spinal stenosis. Eur Spine J 2009;18(06):823-829

37 Barbagallo GM, Olindo G, Corbino L, Albanese V. Analysis of complications in patients treated with the X-Stop Interspinous Process Decompression System: proposal for a novel anatomic scoring system for patient selection and review of the literature. Neurosurgery 2009;65(01):111-119; discussion 119-120 
38 Bowers C, Amini A, Dailey AT, Schmidt MH. Dynamic interspinous process stabilization: review of complications associated with the X-Stop device. Neurosurg Focus 2010;28(06):E8

39 Tamburrelli FC, Proietti L, Logroscino CA. Critical analysis of lumbar interspinous devices failures: a retrospective study. Eur Spine J 2011;20(Suppl 1):S27-S35
40 Kim DH, Tantorski M, Shaw J, et al. Occult spinous process fractures associated with interspinous process spacers. Spine 2011;36(16):E1080-E1085

41 Siewe J, Selbeck M, Koy T, et al. Indications and contraindications: interspinous process decompression devices in lumbar spine surgery. J Neurol Surg A Cent Eur Neurosurg 2015;76(01):1-7 